\title{
Antimutagencity of Phyllamentus Embelica
}

\author{
${ }^{1}$ Maryam Torabizadeh, ${ }^{2}$ Shahrzad saeiadpour, ${ }^{3}$ P.Lakshmi \\ 1,2 (M.Tech.(biotech),Centre forBiotechnology, Jawaharlal Nehru Technological University, Iran) \\ ${ }^{3}$ (PHD ,Associate Professor, Centre forBiotechnology, Jawaharlal Nehru Technological University,India)
}

\begin{abstract}
Cancer is a leading cause of mortality in most countries. It is a third most cause of death worldwide preceded by cardiovascular and infectious diseases. Progress has been made in diagnosis and therapy of cancer by countries. There are many therapeutic strategies including chemotherapy for cancer treatment, but most of them have lots of side effects. Further drug resistance limits the successful outcomes in most cases. Therefore the usage of a variety of traditional remedies which have relatively less harmful side-effects are employed in folk medicine for the treatment of cancer. Moreover herbal remedies which cause less side-effects are believed to be safe and readily accepted by the general public.

Emblica officinalis Gaertn (Phyllanthus emblica, Linn Family Euphorbiaceae) is a medicinal plant described in Ayurveda, the oldest medicinal system in the world and the World Health Organization has approved its medicinal efficacy. Various therapeutic properties of this genus such as antihepatotoxic, antilithic, antihypertensive and most recently anti-HIV have been reported. The most significant properties of Phyllanthus emblica which has been studied is its growth inhibitory activity on various cancer cell lines. also P. emblica has demonstrated antimutagencity activity on diffrent cancer .
\end{abstract}

Keywords : cancer, Phyllanthus emblica, antimutagencity

\section{Introduction}

Indian gooseberry ( Phyllanthus emblica) (Euphorbiaceae) has a distinguished history in Ayurvedic medicine It is ascribed of a number of medicinal properties and as a dietary supplement. The presence of predominantly (poly) phenolic analytes, e.g. ellagic and gallic acids and corilagin, was confirmed.

Many biological and pharmacological functions such as anticancer, cardioprotective, hepatoprotective, antiangiogenic, antioxidant, antisemicarbazide-sensitive amine oxidase, antihypertensive (1-8) antibacterial [9], antiinflammatory, antimutagenic, antioxidant (Scartezzini et al., 2006[10]), antipyretic, antitumour [11]chemopreventive [12] and hepatoprotective activities have been reported in both in vitro and in vivo. The antitumor effect of Phyllanthus species was first verified by its activity against murine B-16 melanoma and P-388 leukemia. The potential anticancer effects of aqueous fruit extract of Phyllantus emblica was tested in several different human cancer cell lines such as A549 (lung), HepG2 (liver), HeLa (cervical), MDA-MB-231 (breast), SKOV3 (ovarian) and SW620 (Colorectal). Phyllantus. emblica extract significantly inhibited the growth of several human cancer cell lines at doses of 50-100 $\mu \mathrm{g} / \mathrm{ml}$. Differential in vitro response of normal cells and tumour cells towards Phyllantus emblica and substantial regression of transplanted tumour in mice fed with Triphala indicates its potential use as an anticancer drug for clinical treatment . [13]

\section{Botanical aspects}

The plant genus Phyllanthus (Euphorbiaceae) is widely distributed in most tropical and subtropical countries. It is a very large genus consisting of approximately 550 to 750 species and is subdivided into 10 or 11 subgenera: Botryanthus, Cicca, Conani, Emblica, Ericocus, Gomphidium, Isocladus, Kirganelia, Phyllanthodendron, Phyllanthus, and Xylophylla[ 14]. Phyllanthus emblica L. is a tree of small or moderate size with a greenish-gray bark and greenish-yellow flowers, formed in axillary clusters. The feathery leaves are linear-oblong, with a rounded base and obtuse or acute apex. It has been suggested that the antioxidative property of amla is the key to its therapeutic effect.

\section{Cancer}

Major feature of all higher eukaryotes is the defined life span of the organism, a property that extends to the individual somatic cells, whose growth and division are highly regulated. A notable exception is provided by cancer cells, which arise as variants that have lost their usual growth control. Cancer is characterized by uncontrolled division and malignant growth of cells. Cancer cells have the ability to grow in inappropriate 
locations or to propagate indefinitely. This may be lethal to the individual organism in which they occur. This type of uncontrolled growth can result from either the presence of tumor specific promoters or by mutations of certain types of genes that regulate cell growth. Materials that have selective cytotoxic effects on cancer cells can be considered as candidate drugs for cancer therapy. Many studies have focused on the evaluation of the antimutagenic and anticarcinogenic activities of P. emblica in order to develop functional foods or drugs to prevent cancers [15].

\subsection{Antimutagenic activity}

In recent years there has been increasing interest in anticarcinogens of plant origin, particularly in edible plants. Antigenotoxic plants can counter or prevent the adverse effects caused by DNA damaging chemicals. Drugs obtained from plants have been investigated for the possible presence of mutagenic and/or carcinogenic substances, following the criteria and norms established for synthetic medicines. There is an increasing interest in the medicinal and dietary plants, which are candidates for the prevention of oxidative damages [16]. Using plant compounds as a source of anticancer agents was initially performed by Hartwell in 1967. He used Podophyllotoxin and its derivatives as anticancer agents [17]. Results from epidemiological studies as well as laboratory investigations suggest an inverse relationship between dietary intake of phytochemicals and human cancer risk [18]. The search for novel antimutagens acting in chemoprevention is a promising field in phytotherapy. [19]

Phenolic compounds and flavonoids are also widely distributed in Phyllanthus emblica which have been reported to exert multiple biological effects, including antioxidant, free radical scavenging abilities, antiinflammatory and anti-carcinogenic etc[20] preventing human cancer.

\section{Antimutagencic activity of Phyllanthus emblica}

Nowadays, the world is directed to depend on nature to decrease the side effects of the drugs. Herbal medicine is the oldest form of health care known to mankind. A lot of studies have been conducted on the antimutagenic and other benefial affects of P. emblica extracts. It has a potent antioxidant activity as it provides a rich source of antioxidant compounds including ascorbic acid, tannins, flavonoids, etc. [21]. Plant polyphenols, especially ellagic acid and tannic acid, are known to protect against skin tumor promotion by inhibition of ornithine decarboxylase activity, hydrogen peroxide production and DNA synthesis [22].

The ability of P. emblica to inhibit in vivo carcinogenesis has been previously reported by several groups. The studies demonstrated the chemopreventive action of P. emblica on hepatocarcinogenesis in rats and skin carcinogenesis induced by croton oil in mice [23]. Ngamkitidechakul et al , 2010 have reported that the aqueous extract of P. emblica induces apoptosis in human cancer cells [24]. The apoptotic effect of aqueous extracts of P. emblica has been reported in human primary osteoclasts using the TUNEL assay (growth inhibitory assay) [25]. Similar observations were noticed in CeHa, a human cervical cancer derived cell line. The induction of apoptosis by phyllantus embelica is important because it has been demonstrated to have promising cancer chemo preventive effects in laboratory experiments[26].

Apoptosis can be divided into two pathways, the extrinsic and intrinsic pathways which involve caspases that are constitutively expressed during the process. Regardless of which pathway is initiated, both will eventually converge and activate Caspase-3 and -7 , which are the execution caspases[27]. According to the researchers at Department of Medical Microbiology, of Medicine Universiti Malaya [28], apoptosis occurred in the cells treated with Phyllanthus as the level of these execution caspases was increased manifold over the basal level of untreated cells. This could be due to the presence of tannins (such as gallic acid and geraniin) in the Phyllanthus extracts which had been shown to be able to induce apoptosis in several human cancer cells [29].

Although the exact bioactive compound(s) in Phyllanthus exerting the antimetastasis effects are not yet identified, but it is already known that Phyllanthus is abundant in flavonoids, phenolic acids and ellagitannins. Many of these bioactive compounds have been shown to exert antimetastatic and apoptosis-inducing effects. Studies conducted at University Malaya indicated that Phyllanthus was able to cause selective toxicity on A549 (lung cancer) and MCF-7 cancer cell lines. In addition, it has the ability to exert inhibitory effects on the critical steps in metastasis, including cell invasion, migration, and invasion. A number of phenolic compounds isolated from the fruit extract are responsible for the antiproliferative component of P. emblica [30]. Its antimetastatic potential could partially be attributed to its capability to induce apoptosis which is associated with the activation of caspases-3 and -7 as well as DNA fragmentation. P. emblica extract was also combined with doxorubicin or cispaltin for treating cancer cell lines of HepG2 (liver carcinoma) and A549 (lung carcinoma). The significance of this finding lies in the fact that doxorubicin and cisplatin are well-known cancer therapeutic agents, but cause high toxicity to normal tissues during cancer therapy. Recent reports show that combination of dietary supplements with known anti-cancer agents in a combination chemotherapy could be used to reduce the systemic toxicity of chemotherapeutic agents [31-32]. Hence Phyllanthus can be used as an important candidate as a chemopreventive agent against cancer. 


\section{Conclusion}

Several new strategies have developed for treating cancer. However side effects can be debilitating and can make life very unpleasant. Hence combination of effective phytochemicals with chemotherapeutic agents would be a promising therapeutic alternative to decrease the side effects on normal tissue.

Genus Phyllanthus is a great source of materials which can control and cause apoptosis in cancer cell lines and moreover, it significantly could be used as a anti mutagenic agent against cancer. Many studies on P. emblica extracts have demonstrated its cytotoxic affect and its ability to inhibit the in vitro proliferation of many tumour cell lines such as MK-1 (human gastric adenocarcinoma) and B16F10 (murine melanoma) [33].

Antimutagenic properties of different plants have been investigated. Aloe vera extracts have shown antioxidant properties in human and animals [34]. Adhami et al, reported anticarcinogenic impact of green tea extract on prostate cancer [35]. Aqueous extracts of Olive leaf have been shown to possess antimutagenic and anti-carcinogenic effects [36]. The anticancer effect of turmeric/curcumin was reported in a study conducted in China on 25 patients with one of five high-risk conditions (Cheng et al). In this study, The present review article points out that amla extracts have good antimutagenic and anti-carcinogenic effects. It can be concluded that Phyllanthus emblica should have a more effective place in treatment because of its antimutagenic and anticarcinogenic property. However more comprehensive research with focus on its bioactive agents is needed for understanding the scope and exact mechanism of action for better application of amla in cancer therapy.

\section{References}

[1] L.Chularojmontri, S. K. Wattanapitayakul, A. Herunsalee, S.Charuchongkolwongse, S. Niumsakul, and S. Srichairat, "Antioxidative and cardioprotective effects of Phyllanthus urinaria L. on

[2] doxorubicin-induced cardiotoxicity," Biological and Pharmaceutical Bulletin, vol. 28, no. 7, pp. 1165-1171, 2005. View at Publisher

[3] K. J. Jeena, K. L. Joy, and R. Kuttan, "Effect of Emblica officinalis,

[4] Phyllanthus amarus and Picrorrhiza kurroa on N-nitrosodiethylamine induced hepatocarcinogenesis," Cancer Letters, vol. 136, no. 1, pp. 11-16, 1999

[5] V. Rajeshkumar and R. Kuttan, "Phyllanthus amarus extract administration increases the life span of rats with hepatocellular carcinoma," Journal of Ethnopharmacology, vol. 73, no. 1-2, pp. 215-219, 2000

[6] R. Pettit, D. E. Schaufelberger, R. A. Nieman, C. Dufresne, and J. A. Saenz-Renauld, “Antineoplastic agents, 177. Isolation and structure of phyllanthostatin 6," Journal of Natural Products, vol. 53, no. 6, pp. 1406-1413, 1990

[7] Powis and D. J. Moore, "High-performance liquid chromatographic assay for the antitumor glycoside phyllanthoside and its stability in plasma of several species," Journal of Chromatography, vol. 342, no. 1, pp. 129-134, 1985

[8] Giridharan, S. T. Somasundaram, K. Perumal et al., "Novel substituted methylenedioxy lignan suppresses proliferation of cancer cells by inhibiting telomerase and activation of c-myc and caspases leading to apoptosis," British Journal of Cancer, vol. 87, no. 1, pp. 98-105, 2002.

[9] Y. Lin, C. C. Wang, Y. L. Lu, W. C. Wu, and W. C. Hou, “Antioxidant, anti-semicarbazide-sensitive amine oxidase, and antihypertensive activities of geraniin isolated from Phyllanthus urinaria," Food and Chemical Toxicology, vol. 46, no. 7, pp. 2485$2492,2008$.

[10] Srirama, U. Senthilkumar, N. Sreejayan et al., "Assessing species admixtures in raw drug trade of Phyllanthus, a hepato-protective plant using molecular tools," Journal of Ethnopharmacology, vol. 130, no. 2, pp. 208-215, 2010

[11] Ahmad I, Mehmood Z, Mohammad F. 1998. Screening of some Indian medicinal plants for their antimicrobial properties. J Ethnopharmacol 62: 183-193.

[12] Gali HU, Perchellet EM, Klish DS et al. 1992. Antitumor-promoting activities of hydrolyzable tannins in mouse skin. Carcinogenesis 13: 715-718.

[13] N.V.Rajeshkumar1, M.Radahakrishna Pillai2, and R.Kuttan1 Amala Cancer Research Centre1, Thrissur; Regional Cancer Centre2, Trivandrum; Kerala, India 2003

[14] Sancheti G, Jindal A, Kumari R et al. 2005. Chemopreventive action of Emblica offi cinalis on skin carcinogenesis in mice.

[15] Asian Pac J Cancer Prev 6: 197-201.khan KH .role of emblica officinalis in medisine_A review botany res int 2009 ;2(4):218-228

[16] UNANDER, D.W., WEBSTER, G.L., and BLUMBERG, B.S. (1995): Usage and bioassays in Phyllanthus (Euphorbiaceae) IV. Clustering of antiviral uses and other effects. J. Ethnopharmacol.

[17] [15 ] K. J. Jeena, K. L. Joy, and R. Kuttan, "Effect of Emblica officinalis, Phyllanthus amarus and Picrorrhiza kurroa on Nnitrosodiethylamine induced hepatocarcinogenesis," Cancer Letters, vol. 136, no. 1, pp. 11-16, 1999.

[18] [16] Ben Sghair M, Boubaker J, Naffati Aicha, Limem I, Skandrani I, Bhouri W, Bouhlel I, Kilani S, Chekir Ghedira L, Ghedira K: Antimutagenic and Antioxidant Potentials of Teucrium Ramosissimum Essential Oil. Chem

[19] Biodiverity 2010, 7:1-10

[20] A. Shams, S. Mehrabian and S. Irian, Assessing the antioxidant and anticarcinogenic activities of virgin olive oil and purified olive oil samples treated with light and heat using the Ames test, International Journal of Microbiology Research, 4 (2012), $173-177$.

[21] S. C. Wu, G. C. Yen, B. S. Wang, C. K. Chiu, W. J .Yend, L. Chang and W. D. Du, Antimutagenic and antimicrobial activities of pu-erh tea, LWT, 40 (2007),506-512.

[22] S. H. Omar, Oleuropein in Olive and its Pharmacological Effects, Sci Pharm, 78 (2010), 133-154.

[23] Scartezzini P, Antognoni F, Raggi MA et al. 2006. Vitamin C content and antioxidant activity of the fruit and of the Ayurvedic preparation of Emblica offi cinalis Gaertn. J Ethnopharmacol 104: 113-118.

[24] Gali HU, Perchellet EM, Klish DS et al. 1992. Antitumor-promoting activities of hydrolyzable tannins in mouse skin. Carcinogenesis 13: 715-718.

[25] Sultana S, Ahmed S, Jahangir T. 2008. Emblica offi cinalis and hepatocarcinogenesis: a chemopreventive study in Wistar rats. J Ethnopharmacol 118: $1-6$.

[26] Penolazzi L, Lampronti I, Borgatti M et al. 2008. Induction of apoptosis of human primary osteoclasts treated with extracts from the medicinal plant Emblica offi cinalis. BMC Complement Altern Med 8: 59.

[27] Gali HU, Perchellet EM, Klish DS et al. 1992. Antitumor-promoting activities of hydrolyzable tannins in mouse skin. Carcinogenesis13: 715-718. 
[28] Wu CC, Lin JP, Yang JS, Chou ST, Chen SC, et al. (2006) Capsaicin inducedm cell cycle arrest and apoptosis in human esophagus epidermoid carcinoma CE $81 \mathrm{~T} / \mathrm{VGH}$ cells through the elevation of intracellular reactive oxygen species and Ca2 productions and caspase-3 activation. Mutat Res 601: 71-82.

[29] Lee SH, Jaganath IB, Wang SM, Sekaran SD (2011) Antimetastatic Effects of Phyllanthus on Human Lung (A549) and Breast (MCF-7) Cancer Cell Lines. PLoS ONE 6(6): e20994.

[30] Lee JC, Tsai CY, Kao JY, Kao MC, Tsai SC, et al. (2008) Geraniin-mediated apoptosis by cleavage of focal adhesion kinase through up-regulation of Fas bligand expression in human melanoma cells. Mol Nutr Food Res 6: 655-663

[31] Raghavan D, Koczwara B, Javle M. Evolving strategies of cytotoxic chemotherapy for advanced prostate cancer. Eur J Cancer. 1997;33:566-574

[32] Von Hoff DD, Layard MW, Basa P, Davis HL Jr, Von Hoff AL, Rozencweig M, Muggia FM. Risk factors for doxorubicininduced congestive heart failure. Ann Intern Med. 1979;91:710-717.

[33] Rajeshkumar NV, Pillai MR, Kuttan R. 2003. Induction of apoptosis in mouse and human carcinoma cell lines by Emblica offi cinalis polyphenols and its effect on chemical carcinogenesis. J Exp Clin Cancer Res 22: 201-212.

[34] Lee SH, Jaganath IB, Wang SM, Sekaran SD (2011) Antimetastatic Effects of Phyllanthus on Human Lung (A549) and Breast (MCF-7) Cancer Cell Lines. PLoS ONE 6(6): e20994. doi:10.1371/journal.pone.0020994

[35] Penolazzi L, Lampronti I, Borgatti M et al. 2008. Induction of apoptosis of human primary osteoclasts treated with extracts from the medicinal plant Emblica offi cinalis. BMC Complement Altern Med 8: 59.

[36] Sakagami H, Kuribayashi N, Iida M et al. 1995. Induction of DNA fragmentation by tannin- and lignin-related substances. 